\title{
Association of genetic polymorphisms in IL-1R1 and IL-1R2 genes with IgA nephropathy in the Han Chinese population
}

\author{
Maowei Xie ${ }^{1, *}$, Daofa Zhang ${ }^{1, *}$, Yin Zhang ${ }^{1, *}$, Xiaohong Yang ${ }^{1}$, Yan Su ${ }^{1}$, Yanni Wang ${ }^{1}$, \\ Haiyang Huang ${ }^{2}$, Hui Han ${ }^{1}$, Wenning Li ${ }^{1}$, Keying Fu ${ }^{2}$, Huiluan Su${ }^{1}$, Wentan $X u^{1}$ and \\ Jiali Wei ${ }^{1}$ \\ ${ }^{1}$ Department of Nephrology, Hainan General Hospital, Haikou Hainan 570311, China \\ ${ }^{2}$ Central Laboratory, Hainan General Hospital, Haikou Hainan 570311, China \\ *These authors contributed equally to this work
}

Correspondence to: Jiali Wei, email: wj1525@163.com

Keywords: IgA nephropathy, IL-1R1, IL-1R2, genetics polymorphism, Chinese Han population

Received: February 13, $2017 \quad$ Accepted: March 23, $2017 \quad$ Published: April 07, 2017

Copyright: Xie et al. This is an open-access article distributed under the terms of the Creative Commons Attribution License 3.0 (CC BY

3.0), which permits unrestricted use, distribution, and reproduction in any medium, provided the original author and source are credited.

\section{ABSTRACT}

Aim: IgA nephropathy (IgAN) is the major cause of end-stage renal disease(ESRD) in Asia and its pathogenesis is influenced by both genetic and environmental factors. Single nucleotide polymorphisms (SNPs) in IL1R1 and IL-1R2 may be associated with susceptibility to IgAN. In this study, we study the association between genetic variants of $I L-1 R 1$ and $I L-1 R 2$ and IgA nephropathy risk in the Chinese Han population.

Result: In the allelic model analysis, the rs10490571 and rs3917225 were associated with a 1.40-fold, and 1.31-fold increased risk of IgA nephropathy, respectively. In the genetic model analysis, the rs10490571 in IL1R1 was associated with a 1.46-fold increased risk of IgAN in the dominant model and 1.36-fold increased risk in the Log-additive model, respectively. However, the rs3218977 in IL1R2 was associated with a 0.71 -fold decrease risk of IgAN in the dominant model and a 0.71 -fold decrease risk in the over-dominant model, respectively. We found four SNPs (rs11674595, rs4851521, rs719250, and rs3218896) constructed four haplotypes in the IL1R2 gene and none of the haplotype was significantly associated with risk of IgAN.

Materials and Methods: A case-control study was conducted including 426 nephropathy patients and 463 healthy controls. Chi-squared tests and genetic model were used to evaluate associations.

Conclusions: These findings suggested that $I L-1 R 1$ and $I L-1 R 2$ polymorphisms may contribute to the development of IgAN.

\section{INTRODUCTION}

$\operatorname{Ig} \mathrm{A}$ nephropathy (IgAN), the most common primary glomerulonephritis in the world, is defined by the predominant IgAN deposition in the glomerular mesangium [1]. The disease mainly in the upper respiratory tract infection and the course of disease may be more severe in individuals of Asian ancestry [2]. the patients with IgAN, the mesangium IgA deposits are just because of the IgA1 subclass and often show with abnormal glycosylation [3, 4], which often accompany with an upper respiratory tract infection, and about $40 \%$ of these patients will develop into end-stage renal disease within the next 20 years [5]. Great efforts have been applied to the diagnosis, monitoring and treatment of the disease. In recent years, transformative and intersecting advances have witnessed in our understanding of the biology, aetiology, and pathology of IgAN. However, the specific pathogenesis of IgAN has not yet fully state, but there is evidence that the risk factors are associated with environmental and genetic play vital roles in the etiology of IgAN [6]. Several evidence support the genetic risk factors, containing differences in ethnic ,distributions in region, and individual variation in the course and prognosis of disease $[7,8]$.

interleukin-1 (IL-1) is a multifunctional proinflammatory cytokine that can be produced by many cell types, including monocytes, activated macrophages, and endothelial cells [9], it plays a key role in autoimmune and inflammatory diseases by activating the expression of genes associated with the innate and adaptive immune response 
[10]. IL-1 influences both coagulation and inflammation, so some studies reported that IL-1 SNPs associate with many immune disease. For example, previous study showed that the haplotype of $I L 1 B, I L 1 R N, I L 1 R 1$, and $I L 1 R 2$ increased the risk of venous thrombosis [11], and IL1/IL1Ra, CTLA-4 and Apo1/Fas genes polymorphisms associate with IgA nephropathy [12]. Interleukin 1 receptor, type $1(I L-1 R 1)$ and Interleukin 1 receptor, type 2 (IL-1R2) are cytokine receptor that belongs to the interleukin 1 receptor family, which is an important mediator involved in many cytokine induced immune and inflammatory responses [13]. Study shows that ILIRI and ILIR2 gene regulate the cell metabolism and the response of immune inflammatory induce by many cytokines $[14,15]$. Morever, epidemiological studies of genes affecting IgAN have been manifested that IgAN are impacted by hereditary factors.

To validate the associations between IgAN and common susceptibility loci identified in previous genomewide association studies (GWAS) [16, 17], we conducted a comprehensive association analysis between $\operatorname{IgAN}$ and 11 susceptible SNPs in the ILIRI and ILIR2 gene, to further clarify their potential roles in disease and reveals the association between common SNPs and IgAN risk in the Chinese Han population. The study is to evaluate a positive finding from a previous study, to provide credibility that the initial finding is valid.

\section{RESULTS}

\section{Characteristics of the participants}

This study involved 889 subjects, including 426 patients (278 males and 148 females; age at diagnosis: $33 \pm 12.1$ years) and 463 healthy controls (265 males and 198 females; age: $50 \pm 11.8$ years).There were statistical differences in age and sex distribution between the case and control groups (Table 1).

\section{The associations between IL1R1 and IL1R1 SNPs and IgAN}

11 tSNPs within the ILIRI and ILIR2 locus were genotyped in IgAN patients and healthy controls (Table 2). Two SNPs (rs12712127 and rs3917318) were excluded for significant deviation from Hardy-Weinberg equilibrium $(p<0.05)$, A $\chi 2$ analysis revealed that rs 10490571 and rs3917225 in IL1R1 were significantly associated with increasing $\operatorname{IgAN}$ risk (rs10490571, OR $=1.40,95 \%$ $\mathrm{CI}=1.102-1.779, p=0.005 ; \mathrm{rs} 3917225, \mathrm{OR}=1.31,95 \%$ $\mathrm{CI}=1.080-1.592, p=0.006)$, respectively.

\section{Associations between genotype frequencies and IgAN risk}

As shown in Table 3, our analyses showed that the genotype "C/A-C/C" of rs10490571 in the ILIRI gene was associated with an increased risk of $\operatorname{IgAN}$ in the dominant model (adjusted OR $=1.46,95 \% \mathrm{CI}, 1.03-2.07, P=0.035$ ) and $\log$-additive model (adjusted $\mathrm{OR}=1.36,95 \% \mathrm{CI}, 1.01-$ 1.83, $P=0.04$ ), respectively. The genotype "G/A" of rs4851527 in the IL1R2 gene was significantly associated with an increased risk of IgAN, based on the results from the over-dominant model (adjusted OR $=1.43 ; 95 \%$ $\mathrm{CI}=1.02-2.00, P=0.038)$. In contrast, We found that the rs3218977 in the IL1R2 gene was significantly associated with a decreased risk of $\operatorname{IgAN}$ under the dominant model(adjusted OR $=0.71 ; 95 \% \mathrm{CI}=0.51-0.99, P=0.044$ for the "G/A-G/G" genotype) and over-dominant model (adjusted OR $=0.71 ; 95 \% \mathrm{CI}=0.50-1.00, P=0.048$ for the "G/A" genotype), respectively.

\section{Associations between haplotype analyses and IgAN risk}

LD and haplotype analyses of the SNPs in the case and control samples were further studied. However, the four candidate SNPs in the ILIR2 gene have showed strong linkage (Figure 1). We found that none of these SNPs showed evidence of interaction with age or gender of IgAN patients. As is shown in Table 4, the result for the IL1R2 haplotype was not found to be associated with a risk of $\operatorname{IgAN}$, because the $p$ value have no statistical difference. In addition, we have not found any association between ILIRI haplotype and the risk of IgAN.

\section{DISCUSSION}

Based on results from recent GWAS and previous studies, we chose to analyze 11 tSNPs in chromosomes 2 in our case control study. Using genetic model analysis, we found that two tSNPs (rs4851527, rs10490571) were associated with an increasing risk of IgAN. These results suggest that polymorphisms in these cytokine genes may play an important role in the risk of $\operatorname{IgAN}$ in the Han Chinese population.

Interleukin-1 (IL-1), as a family of multifunctional proinflammatory cytokine, plays a key role in autoimmune and inflammatory diseases by activating the expression of genes associated with the innate and adaptive immune response [10]. The IL-1 superfamily comprises the agonists $I L-1 \alpha$ and $I L-1 \beta$ (predominant form in humans), and their antagonist $I L-1 R a$ and both $I L-1$ agonists can bind to $I L-1$ receptor type $1(I L-1 R I)$ and the "decoy" receptor IL-1 type $2(I L-1 R 2)[18,19]$. ILIRI, as a Protein Coding gene, is located in a cluster of related cytokine receptor genes on chromosome $2 \mathrm{q} 12$, which belongs to the interleukin-1 receptor family and encodes a cytokine receptor [20]. It is an important mediator involved in many cytokine-induced immune and inflammatory responses [21]. IL1R1 resulting from the SNPs (rs10490571 and rs3917225) may alter the combination of ILIRI and IL-1 on the cell surface significantly and 
Table 1: General characteristics the of this study population

\begin{tabular}{|c|c|c|c|c|c|}
\hline variable & cases $(n=426)$ & $\%$ & controls $(n=463)$ & $\%$ & $P$ value \\
\hline sex & & & & & $<0.05$ \\
\hline Male & 278 & $31.3 \%$ & 265 & $29.8 \%$ & \\
\hline Female & 148 & $16.6 \%$ & 198 & $22.3 \%$ & \\
\hline Age, $y r($ mean \pm SD $)$ & $33.2 \pm 12.1$ & & $50.6 \pm 11.8$ & & $<0.001$ \\
\hline
\end{tabular}

Table 2: Allele frequencies in cases and controls and odds ratio estimates for IgAN risk

\begin{tabular}{|c|c|c|c|c|c|c|c|c|c|}
\hline \multirow{2}{*}{ SNP } & \multirow{2}{*}{ Position } & \multirow{2}{*}{ Gene(s) } & \multirow{2}{*}{ Locus } & \multirow{2}{*}{$\begin{array}{c}\text { Alleles } \\
\text { (A/B) }\end{array}$} & \multicolumn{2}{|c|}{ MAF } & \multirow{2}{*}{$\begin{array}{c}\text { HWE } P \\
\text { Value }\end{array}$} & \multirow{2}{*}{ OR $(95 \% \mathrm{CI})$} & \multirow{2}{*}{$P$ value } \\
\hline & & & & & case & control & & & \\
\hline rs 11674595 & 102610992 & IL1R2 & $2 q 11.2$ & $\mathrm{C} / \mathrm{T}$ & 0.204 & 0.211 & 0.78 & $0.95(0.76-1.20)$ & 0.685 \\
\hline rs4851527 & 102622376 & IL1R2 & $2 q 11.2$ & $\mathrm{~A} / \mathrm{G}$ & 0.312 & 0.288 & 0.142 & $1.12(0.91-1.37)$ & 0.284 \\
\hline rs719250 & 102623718 & IL1R2 & $2 q 11.2$ & $\mathrm{~T} / \mathrm{C}$ & 0.314 & 0.313 & 0.746 & $1.01(0.82-1.23)$ & 0.954 \\
\hline rs3218896 & 102631652 & IL1R2 & $2 q 11.2$ & $\mathrm{C} / \mathrm{T}$ & 0.157 & 0.157 & 0.596 & $1.00(0.78-1.30)$ & 0.978 \\
\hline rs3218977 & 102641201 & IL1R2 & $2 q 11.2$ & $\mathrm{G} / \mathrm{A}$ & 0.216 & 0.252 & 0.175 & $0.82(0.66-1.02)$ & 0.077 \\
\hline rs2072472 & 102643019 & IL1R2 & $2 q 11.2$ & $\mathrm{G} / \mathrm{A}$ & 0.198 & 0.206 & 0.672 & $0.95(0.75-1.20)$ & 0.679 \\
\hline rs10490571 & 102717337 & IL1R1 & $2 q 12.1$ & $\mathrm{~T} / \mathrm{C}$ & 0.217 & 0.165 & 0.867 & $1.40(1.10-1.78)$ & $0.006^{*}$ \\
\hline rs 12712127 & 102726661 & IL1R1 & $2 q 12.1$ & $\mathrm{G} / \mathrm{A}$ & 0.262 & 0.21 & $0.000^{\mathrm{a}}$ & $1.34(1.07-1.67)$ & 0.01 \\
\hline rs956730 & 102758116 & IL1R1 & $2 q 12.1$ & $\mathrm{~A} / \mathrm{G}$ & 0.249 & 0.261 & 0.147 & $0.94(0.76-1.17)$ & 0.583 \\
\hline rs3917225 & 102769302 & IL1R1 & $2 q 12.1$ & $\mathrm{~T} / \mathrm{C}$ & 0.405 & 0.342 & 0.409 & $1.31(1.08-1.59)$ & $0.006^{*}$ \\
\hline rs3917318 & 102792760 & IL1R1 & $2 q 12.1$ & $\mathrm{G} / \mathrm{A}$ & 0.435 & 0.485 & $0.012^{\mathrm{a}}$ & $0.82(0.68-0.99)$ & 0.037 \\
\hline
\end{tabular}

HWE: Hardy-Weinberg equilibrium; SNP: Single-nucleotide polymorphism; OR odds ratio; 95\% CI: 95\% confidence interval. a Site with HWE $P \leq 0.05$ excluded.

${ }^{*} p \leq 0.05$ indicates statistical significant.

hence modulate the inflammatory processes associated with glomerular mesangial area destruction accordingly. This assumption was in accordance with previous findings that the degree of $I L I R I$ expression on the cell surface affected the response of cells to $I L-1$ [22]. Recent studies revealed that $I L 1 R I$ expression was observably increased in several types of disease, including knee osteoarthritis [11], Prostate Carcinoma [23], hand osteoarthritis [24] and Inflammatory Bowel Disease [25]. However, we have not found any evidence for the role of heredity between ILIRI and IgAN susceptibility in previous studies. In our casecontrol study, we found that rs10490571, as the intronic SNP within the ILIRI gene, were markedly associated with IgAN risk according to both genotype and allele association analysis in a Chinese population. Based on the result of the study, the genotype of rs 10490571 predicted an increased 1.46-fold and 1.36-fold IgAN risk, Therefore, this result indicate that ILIRI may play a pivotal role in IgAN and more samples and functional test are require to confirm our result.

$I L-1 R 2$, as a decoy receptor, is located on $2 \mathrm{q} 11.2$ in the human genome, which is principally expressed by neutrophils, B-cells, monocytes, and macrophages [26]. ILIR2 is known to be a molecular decoy that sequesters $I L-1 b$, and blocks the initiation of downstream signaling, thereby preventing inflammation. The $I L-1 R 2$ receptor as a decrease of inflammation in several complex diseases, such as Ankylosing spondylitis [27], Arthritis [28], atherosclerosis [29] and endometriosis [30]. However, study based on this ILIR2 gene polymorphism is rare and have no report association between the SNP $I L 1 R 2$ and IgAN risk. As part of this study, the GA genotype of rs 4851527 exhibited increase IgAN risk. But the GA genotype of rs3218977 showed decrease IgAN risk. Hence, $I L I R 2$ gene may play an essential function in affecting IgAN. But the distinct role of $I L-1 R 2$, especially in $\operatorname{IgAN}$, remains unknown and is worth our further research.

Some potential limitations of our current study should be considered when decipher the results. Firstly, we only included $426 \mathrm{IgAN}$ patients and 463 health controls, so the sample size of our study may be small. Secondly, selection bias was inevitable. Thirdly, both IgAN patients and controls were gathered from a single hospital and therefore it may not be representative of the common population. Finally, associations between ILIRI and ILIR2 polymorphisms and clinicopathological disease type were not evaluated in this study. Additional studies are needed to illuminate the genetic mechanisms underlying IgAN by fine-mapping the susceptibility regions of the variants.

To sum up, In our study, we confirmed two genes $(I L 1 R 1$ and $I L 1 R 2)$ are associated with risk of IgAN in 
Table 3: Relationships between $I L 1 R 1$ and $I L 1 R 2$ polymorphism and IgA nephropathy risk

\begin{tabular}{|c|c|c|c|c|c|c|c|c|c|c|c|}
\hline \multirow{2}{*}{ Gene } & \multirow{2}{*}{ SNP } & \multirow{2}{*}{ Model } & \multirow{2}{*}{ Genotype } & \multirow{2}{*}{ control } & \multirow{2}{*}{ case } & \multicolumn{2}{|c|}{ Before adjusted } & \multicolumn{2}{|c|}{ After adjusted } & \multirow{2}{*}{ AIC } & \multirow{2}{*}{ BIC } \\
\hline & & & & & & OR $(95 \%$ CI $)$ & $P^{a}$ & OR $(95 \%$ CI $)$ & $P^{b}$ & & \\
\hline \multirow[t]{20}{*}{$I L I R I$} & rs10490571 & Codominant & $\mathrm{C} / \mathrm{C}$ & $323(69.8 \%)$ & $258(61.9 \%)$ & 1 & $0.022^{*}$ & 1 & 0.11 & 867.4 & 891.3 \\
\hline & & & $\mathrm{T} / \mathrm{C}$ & $127(27.4 \%)$ & $137(32.9 \%)$ & $1.35(1.01-1.81)$ & & $1.44(1.00-2.08)$ & & & \\
\hline & & & $\mathrm{T} / \mathrm{T}$ & $13(2.8 \%)$ & $22(5.3 \%)$ & $2.12(1.05-4.29)$ & & $1.57(0.68-3.64)$ & & & \\
\hline & & Dominant & $\mathrm{C} / \mathrm{C}$ & $323(69.8 \%)$ & $258(61.9 \%)$ & 1 & $0.014^{*}$ & 1 & $0.035^{*}$ & 865.4 & 884.5 \\
\hline & & & $\mathrm{T} / \mathrm{C}-\mathrm{T} / \mathrm{T}$ & $140(30.2 \%)$ & $159(38.1 \%)$ & $1.42(1.07-1.88)$ & & $1.46(1.03-2.07)$ & & & \\
\hline & & Recessive & $\mathrm{C} / \mathrm{C}-\mathrm{T} / \mathrm{C}$ & $450(97.2 \%)$ & $395(94.7 \%)$ & 1 & 0.061 & 1 & 0.42 & 869.2 & 888.3 \\
\hline & & & $\mathrm{T} / \mathrm{T}$ & $13(2.8 \%)$ & $22(5.3 \%)$ & $1.93(0.96-3.88)$ & & $1.40(0.61-3.23)$ & & & \\
\hline & & Overdominant & $\mathrm{C} / \mathrm{C}-\mathrm{T} / \mathrm{T}$ & $336(72.6 \%)$ & $280(67.2 \%)$ & 1 & 0.08 & 1 & 0.067 & 866.5 & 885.6 \\
\hline & & & $\mathrm{T} / \mathrm{C}$ & $127(27.4 \%)$ & $137(32.9 \%)$ & $1.29(0.97-1.73)$ & & $1.40(0.98-2.02)$ & & & \\
\hline & & Log-additive & --- & --- & --- & $1.39(1.10-1.76)$ & $0.0062^{*}$ & $1.36(1.01-1.83)$ & $0.04^{*}$ & 865.6 & 884.8 \\
\hline & rs3917225 & Codominant & $\mathrm{A} / \mathrm{A}$ & $204(44.2 \%)$ & $157(37.6 \%)$ & 1 & $0.022^{*}$ & 1 & 0.33 & 868 & 891.9 \\
\hline & & & $\mathrm{G} / \mathrm{A}$ & $200(43.3 \%)$ & $182(43.6 \%)$ & $1.18(0.89-1.58)$ & & $1.19(0.83-1.70)$ & & & \\
\hline & & & $\mathrm{G} / \mathrm{G}$ & $58(12.6 \%)$ & $78(18.7 \%)$ & $1.75(1.17-2.60)$ & & $1.43(0.88-2.34)$ & & & \\
\hline & & Dominant & $\mathrm{A} / \mathrm{A}$ & $204(44.2 \%)$ & $157(37.6 \%)$ & 1 & 0.05 & 1 & 0.2 & 866.5 & 885.7 \\
\hline & & & $\mathrm{G} / \mathrm{A}-\mathrm{G} / \mathrm{G}$ & $258(55.8 \%)$ & $260(62.4 \%)$ & $1.31(1.00-1.72)$ & & $1.25(0.89-1.75)$ & & & \\
\hline & & Recessive & A/A-G/A & $404(87.5 \%)$ & $339(81.3 \%)$ & 1 & $0.012^{*}$ & 1 & 0.24 & 866.8 & 886 \\
\hline & & & $\mathrm{G} / \mathrm{G}$ & $58(12.6 \%)$ & $78(18.7 \%)$ & $1.60(1.11-2.32)$ & & $1.31(0.83-2.06)$ & & & \\
\hline & & Overdominant & A/A-G/G & $262(56.7 \%)$ & $235(56.4 \%)$ & 1 & 0.92 & 1 & 0.68 & 868 & 887.1 \\
\hline & & & $\mathrm{G} / \mathrm{A}$ & $200(43.3 \%)$ & $182(43.6 \%)$ & $1.01(0.78-1.33)$ & & $1.07(0.77-1.50)$ & & & \\
\hline & & Log-additive & --- & --- & -- & $1.29(1.07-1.56)$ & $0^{0.008}$ & $1.19(0.95-1.51)$ & 0.14 & 866 & 885.1 \\
\hline \multirow[t]{20}{*}{$I L I R 2$} & rs 4851527 & Codominant & $\mathrm{G} / \mathrm{G}$ & $241(52 \%)$ & $195(46.8 \%)$ & 1 & 0.2 & 1 & 0.12 & 867.5 & 891.4 \\
\hline & & & $\mathrm{G} / \mathrm{A}$ & $177(38.2 \%)$ & $184(44.1 \%)$ & $1.28(0.97-1.70)$ & & $1.43(1.01-2.03)$ & & & \\
\hline & & & $\mathrm{A} / \mathrm{A}$ & $45(9.7 \%)$ & $38(9.1 \%)$ & $1.04(0.65-1.67)$ & & $0.99(0.55-1.79)$ & & & \\
\hline & & Dominant & $\mathrm{G} / \mathrm{G}$ & $241(52 \%)$ & $195(46.8 \%)$ & 1 & 0.12 & 1 & 0.088 & 866.9 & 886.1 \\
\hline & & & $\mathrm{G} / \mathrm{A}-\mathrm{A} / \mathrm{A}$ & $222(48 \%)$ & $222(53.2 \%)$ & $1.24(0.95-1.61)$ & & $1.33(0.96-1.86)$ & & & \\
\hline & & Recessive & G/G-G/A & $418(90.3 \%)$ & $379(90.9 \%)$ & 1 & 0.76 & 1 & 0.56 & 869.5 & 888.6 \\
\hline & & & $\mathrm{A} / \mathrm{A}$ & $45(9.7 \%)$ & $38(9.1 \%)$ & $0.93(0.59-1.47)$ & & $0.85(0.48-1.49)$ & & & \\
\hline & & Overdominant & $\mathrm{G} / \mathrm{G}-\mathrm{A} / \mathrm{A}$ & $286(61.8 \%)$ & $233(55.9 \%)$ & 1 & 0.076 & 1 & $0^{0.038} 8^{*}$ & 865.5 & 884.7 \\
\hline & & & $\mathrm{G} / \mathrm{A}$ & $177(38.2 \%)$ & $184(44.1 \%)$ & $1.28(0.97-1.67)$ & & $1.43(1.02-2.00)$ & & & \\
\hline & & Log-additive & --- & --- & -- & $1.12(0.91-1.37)$ & 0.29 & $1.14(0.89-1.47)$ & 0.29 & 868.7 & 887.9 \\
\hline & rs3218977 & Codominant & $\mathrm{A} / \mathrm{A}$ & $264(57.1 \%)$ & $263(63.2 \%)$ & 1 & 0.18 & 1 & 0.12 & 867 & 890.9 \\
\hline & & & $\mathrm{G} / \mathrm{A}$ & $163(35.3 \%)$ & $126(30.3 \%)$ & $0.78(0.58-1.04)$ & & $0.69(0.48-0.98)$ & & & \\
\hline & & & $\mathrm{G} / \mathrm{G}$ & $35(7.6 \%)$ & $27(6.5 \%)$ & $0.77(0.46-1.32)$ & & $0.81(0.41-1.60)$ & & & \\
\hline & & Dominant & $\mathrm{A} / \mathrm{A}$ & $264(57.1 \%)$ & $263(63.2 \%)$ & 1 & 0.066 & 1 & $0.044^{*}$ & 865.2 & 884.3 \\
\hline & & & $\mathrm{G} / \mathrm{A}-\mathrm{G} / \mathrm{G}$ & $198(42.9 \%)$ & $153(36.8 \%)$ & $0.78(0.59-1.02)$ & & $0.71(0.51-0.99)$ & & & \\
\hline & & Recessive & A/A-G/A & $427(92.4 \%)$ & $389(93.5 \%)$ & 1 & 0.53 & 1 & 0.84 & 869.2 & 888.3 \\
\hline & & & $\mathrm{G} / \mathrm{G}$ & $35(7.6 \%)$ & $27(6.5 \%)$ & $0.85(0.50-1.43)$ & & $0.93(0.48-1.81)$ & & & \\
\hline & & Overdominant & $\mathrm{A} / \mathrm{A}-\mathrm{G} / \mathrm{G}$ & $299(64.7 \%)$ & $290(69.7 \%)$ & 1 & 0.12 & 1 & $0.048^{*}$ & 865.4 & 884.5 \\
\hline & & & $\mathrm{G} / \mathrm{A}$ & $163(35.3 \%)$ & $126(30.3 \%)$ & $0.80(0.60-1.06)$ & & $0.71(0.50-1.00)$ & & & \\
\hline & & Log-additive & --- & -- & -- & $0.83(0.67-1.03)$ & 0.089 & $0.79(0.61-1.04)$ & 0.092 & 866.4 & 885.5 \\
\hline
\end{tabular}


Table 4: Haplotype analysis results in this study

\begin{tabular}{|c|c|c|c|c|c|c|}
\hline \multirow{2}{*}{ SNPs } & \multirow{2}{*}{ haplotype } & \multirow{2}{*}{ Freq } & \multicolumn{2}{|c|}{ without adjusted } & \multicolumn{2}{|c|}{ with adjusted } \\
\hline & & & OR $(95 \%$ CI $)$ & $P$ & OR $(95 \%$ CI) & $P^{a}$ \\
\hline \multirow{3}{*}{$\begin{array}{c}\text { rs } 11674595 / \\
\text { rs4851521 }\end{array}$} & $\mathrm{TG}$ & 0.493 & 1 & --- & 1 & --- \\
\hline & TA & 0.298 & $1.13(0.91-1.40)$ & 0.27 & $1.18(0.90-1.54)$ & 0.23 \\
\hline & $\mathrm{CG}$ & 0.207 & $1.00(0.78-1.28)$ & 0.98 & $1.04(0.76-1.43)$ & 0.8 \\
\hline \multirow{3}{*}{$\begin{array}{l}\text { rs719250/ } \\
\text { rs3218896 }\end{array}$} & $\mathrm{CT}$ & 0.686 & 1 & --- & 1 & --- \\
\hline & TT & 0.157 & $1.00(0.76-1.30)$ & 0.97 & $1.05(0.75-1.46)$ & 0.78 \\
\hline & $\mathrm{TC}$ & 0.156 & $1.01(0.78-1.31)$ & 0.94 & $0.95(0.68-1.32)$ & 0.76 \\
\hline
\end{tabular}

Abbreviations: $\mathrm{CI}=$ confidence interval; $\mathrm{OR}=$ odds ratio; $\mathrm{SNP}=$ single nucleotide polymorphism.

$\mathrm{Pa}^{\mathrm{a}}$ : Adjusted by gender and age.

Han Chinese population for the first time, which may provide new data to facilitate earlier diagnosis and promote early prevention, and shed light on the new candidate genes and new ideas for the study of subsequent occurrence mechanism of IgAN. Therefore, more studies should investigate these SNPs using more clinical data with bigger samples.

\section{MATERIALS AND METHODS}

\section{Ethics statement}

The study protocol was approved by the ethics committee of the First Affiliated Hospital of Xi'an Jiaotong University. Written informed consent was obtained from all participants after a full explanation of the study. The experimental protocol was implemented in accordance with the approved guidelines.

\section{Subjects}

We recruited a total of 426 patients, which were diagnosed with IgAN (148 female and 278 male, mean age of 33+12.1 years)by renal biopsy were enrolled from the First Affiliated Hospital of Xi'an Jiaotong University from March 2011 to April 2016. The controls were 463 healthy subjects (265 males and 198 females, mean age of $50 \pm$ 11.8 years) recruited from routine healthy examinations in the same hospitals. All subjects were from the Chinese Han population living in Xi'an. All the patients were recently diagnosed and histologically confirmed to suffer from IgAN according to the renal biopsy, and they had not received any systemic treatment before the time of examination. Besides, patients with cancer, infection, secondary IgAN (Secondary IgAN is seen most commonly in patients with liver disease or mucosal inflammation, in particular affecting the gastrointestinal tract), other renal

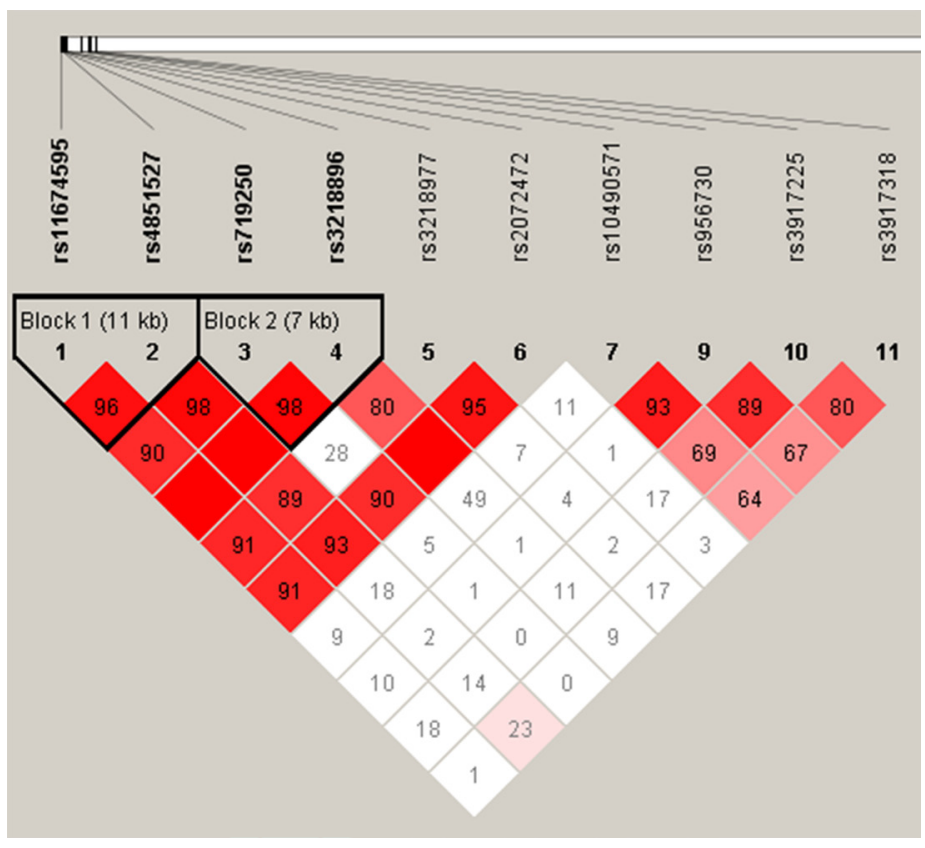

Figure 1: Linkage disequilibrium (LD) plots containing four SNPs from IL1R2. 
diseases and autoimmune diseases were excluded. The exclusion criteria for healthy subjects included the chronic disease, central nervous system-related disease, and conditions involving vital organs (liver, heart, lung, brain) and more aggressive metabolic and endocrinological disease. SNP selection and genotyping

All 11 SNPs in the ILIRI and ILIR2 gene with minor allele frequencies $>5 \%$ in the HapMap (http:// www.hapmap. org) Han Chinese population. Blood samples were collected in tubes containing ethylene diaminetetraacetic acid (EDTA) and stored at -80C after centrifugating at $1,500 \mathrm{rpm}$ for $10 \mathrm{~min}$. Genomic DNA from whole blood was extracted using the GoldMag DNA Purification Kit (GoldMag Co. Ltd, Xi'an City, China), and the purity and concentration was measured utilizing an ultraviolet spectrophotometer (Nanodrop, Thermo Scientific, Waltham, MA). The Sequenom MassARRAY Assay Design 3.0 software was used to design Multiplexed SNP MassEXTEND assay. SNP genotyping was performed by using Sequenom MassARRAY RS1000 according to the standard protocol. Sequenom Typer 4.0 software was used for data management and analysis.

\section{Statistical analysis}

We performed Statistical analyses was using Microsoft Excel and SPSS 16.0 (SPSS, Chicago,IL, USA) to In this study, all $p$ values were two-sided ( $p \leq 0.05$ was considered as achieving the threshold of statistical significance). Each SNP frequency in the control subjects was tested for deviation from Hardy-Weinberg equilibrium (HWE) by the Fisher's test. Calculate the genotype and allele frequencies in patients and controls were also compared using the $\chi^{2}$ test. Odds ratio (OR) values and $95 \%$ confidence intervals (CIs) measured risk allele effect size using unconditional logistic regression analysis [31]. Five genetic models (codominant, dominant, recessive, overdominant, and logadditive) were used to evaluate potential association of $I L 1 R 1$ and ILIR2 polymorphisms with risk and clinical parameters of IgAN. Statistical analyses were performed using Microsoft Excel and the SPSS 17.0 statistical package (SPSS Inc, Chicago, Illinois, USA). Finally, the Haploview were used to construct haplotype and genetic association at significant polymorphism loci and to estimate the pairwise linkage disequilibrium (LD), haplotype constru software (version4.2) and SHEsis software platform (http://www. nhgg.org/analysis/) ction, and genetic association at polymorphism loci $[32,33]$.

\section{ACKNOWLEDGMENTS AND FUNDING}

This work was supported by National Natural Science Foundation of China (No.81560124).We are grateful to the patients and control subjects for their participation in this study. We also thank the staff of the First Affiliated Hospital of Xi'an Jiaotong University) obtained the blood samples and performed data collection for this study.

\section{CONFLICTS OF INTEREST}

The authors have declared that no competing interest exists.

\section{REFERENCES}

1. Roberts IS. Pathology of IgA nephropathy. Nat Rev Nephrol. 2014; 10:445-54. doi: 10.1038/nrneph.2014.92.

2. Niu D, Gao Y, Xie L, Sun J, Lu W, Jin G, Hao Y, Zhang Y, Yin A, Geng Y, Zhang W, Chen C, Li S. Genetic polymorphisms in TNFSF13 and FDX1 are associated with IgA nephropathy in the Han Chinese population. Hum Immunol. 2015; 76:831-5. doi: 10.1016/j.humimm.2015.09.044.

3. Conley ME, Cooper MD, Michael AF. Selective deposition of immunoglobulin A1 in immunoglobulin A nephropathy, anaphylactoid purpura nephritis, and systemic lupus erythematosus. J Clin Invest. 1980; 66:1432-6. doi: 10.1172/jci109998.

4. Coppo R, Amore A. Aberrant glycosylation in $\operatorname{IgA}$ nephropathy (IgAN). Kidney Int. 2004; 65:1544-7. doi: 10.1111/j.1523-1755.2004.05407.x.

5. D'Amico G. Natural history of idiopathic IgA nephropathy and factors predictive of disease outcome. Semin Nephrol. 2004; 24:179-96.

6. Hsu SI, Ramirez SB, Winn MP, Bonventre JV, Owen WF. Evidence for genetic factors in the development and progression of $\operatorname{IgA}$ nephropathy. Kidney Int. 2000; 57:1818-35. doi: 10.1046/j.1523-1755.2000.00032.x.

7. Scolari F. Inherited forms of IgA nephropathy. J Nephrol. 2003; 16:317-20.

8. Beerman I, Novak J, Wyatt RJ, Julian BA, Gharavi AG. The genetics of IgA nephropathy. Nat Clin Pract Nephrol. 2007; 3:325-38. doi: 10.1038/ncpneph0492.

9. Mizel SB. The interleukins. Faseb j. 1989; 3:2379-88.

10. Dinarello CA. The IL-1 family and inflammatory diseases. Clin Exp Rheumatol. 2002; 20:S1-13.

11. van Minkelen R, de Visser MC, Houwing-Duistermaat JJ, Vos HL, Bertina RM, Rosendaal FR. Haplotypes of IL1B, IL1RN, IL1R1, and IL1R2 and the risk of venous thrombosis. Arterioscler Thromb Vasc Biol. 2007; 27:1486-91. doi: 10.1161/atvbaha.107.140384.

12. Gorgi Y, Sfar I, Goucha R, Aouadi H, Amri M, Makhlouf M, Ben Romdhane T, Cherif M, Jendoubi-Ayed S, Ben Abdallah T, Ayed K. [IL1/IL1 Ra, CTLA-4 and Apo1/Fas genes polymorphisms and susceptibility to IgA nephropathy in Tunisian patients]. Tunis Med. 2010; 88:789-93.

13. Sims JE, Dower SK. Interleukin-1 receptors. Eur Cytokine Netw. 1994; 5:539-46.

14. Dinarello CA. The interleukin-1 family: 10 years of discovery. Faseb j. 1994; 8:1314-25. 
15. Rock FL, Hardiman G, Timans JC, Kastelein RA, Bazan JF. A family of human receptors structurally related to Drosophila Toll. Proc Natl Acad Sci USA. 1998; 95:588-93.

16. Gharavi AG, Kiryluk K, Choi M, Li Y, Hou P, Xie J, SannaCherchi S, Men CJ, Julian BA, Wyatt RJ, Novak J, He JC, Wang H, et al. Genome-wide association study identifies susceptibility loci for IgA nephropathy. Nat Genet. 2011; 43:321-7. doi: 10.1038/ng.787.

17. Yu XQ, Li M, Zhang H, Low HQ, Wei X, Wang JQ, Sun LD, Sim KS, Li Y, Foo JN, Wang W, Li ZJ, Yin XY, et al. A genome-wide association study in Han Chinese identifies multiple susceptibility loci for IgA nephropathy. Nat Genet. 2011; 44:178-82. doi: 10.1038/ng.1047.

18. Dinarello CA. Interleukin-1, interleukin-1 receptors and interleukin-1 receptor antagonist. Int Rev Immunol. 1998; 16:457-99. doi: 10.3109/08830189809043005.

19. Sims JE. IL-1 and IL-18 receptors, and their extended family. Curr Opin Immunol. 2002; 14:117-22.

20. Vasilyev FF, Silkov AN, Sennikov SV. Relationship between interleukin- 1 type 1 and 2 receptor gene polymorphisms and the expression level of membrane-bound receptors. Cell Mol Immunol. 2015; 12:222-30. doi: 10.1038/cmi.2014.43.

21. Colotta F, Dower SK, Sims JE, Mantovani A. The type II 'decoy' receptor: a novel regulatory pathway for interleukin 1. Immunol Today. 1994; 15:562-6. doi: 10.1016/0167569990217-8.

22. Sims JE, Gayle MA, Slack JL, Alderson MR, Bird TA, Giri JG, Colotta F, Re F, Mantovani A, Shanebeck K. Interleukin 1 signaling occurs exclusively via the type I receptor. Proc Natl Acad Sci USA. 1993; 90:6155-9.

23. Ricote M, Garcia-Tunon I, Bethencourt FR, Fraile B, Paniagua R, Royuela M. Interleukin-1 (IL-1alpha and IL1beta) and its receptors (IL-1RI, IL-1RII, and IL-1Ra) in prostate carcinoma. Cancer. 2004; 100:1388-96. doi: 10.1002/cncr.20142.

24. Nakki A, Kouhia ST, Saarela J, Harilainen A, Tallroth K, Videman T, Battie MC, Kaprio J, Peltonen L, Kujala UM. Allelic variants of IL1R1 gene associate with severe hand osteoarthritis. BMC Med Genet. 2010; 11:50. doi: 10.1186/1471-2350-11-50.
25. Latiano A, Palmieri O, Pastorelli L, Vecchi M, Pizarro TT, Bossa F, Merla G, Augello B, Latiano T, Corritore G, Settesoldi A, Valvano MR, D'Inca R, et al. Associations between genetic polymorphisms in IL-33, IL1R1 and risk for inflammatory bowel disease. PLoS One. 2013; 8:e62144. doi: 10.1371/journal.pone.0062144.

26. Peters VA, Joesting JJ, Freund GG. IL-1 receptor 2 (IL-1R2) and its role in immune regulation. Brain Behav Immun. 2013; 32:1-8. doi: 10.1016/j.bbi.2012.11.006.

27. Xia Y, Liu YQ, Chen K, Wang LC, Ma CY, Zhao YR. Association of IL-1R2 genetic polymorphisms with the susceptibility of ankylosing spondylitis in Northern Chinese Han population. Mod Rheumatol. 2015; 25:908-12. doi: 10.3109/14397595.2015.1024302.

28. Shimizu K, Nakajima A, Sudo K, Liu Y, Mizoroki A, Ikarashi T, Horai R, Kakuta S, Watanabe T, Iwakura Y. IL-1 receptor type 2 suppresses collagen-induced arthritis by inhibiting IL-1 signal on macrophages. J Immunol. 2015; 194:3156-68. doi: 10.4049/jimmunol.1402155.

29. Pou J, Martinez-Gonzalez J, Rebollo A, Rodriguez C, Rodriguez-Calvo R, Martin-Fuentes P, Cenarro A, Civeira F, Laguna JC, Alegret M. Type II interleukin-1 receptor expression is reduced in monocytes/macrophages and atherosclerotic lesions. Biochim Biophys Acta. 2011; 1811:556-63. doi: 10.1016/j.bbalip.2011.05.014.

30. Akoum A, Jolicoeur C, Kharfi A, Aube M. Decreased expression of the decoy interleukin-1 receptor type II in human endometriosis. Am J Pathol. 2001; 158:481-9. doi: 10.1016/s0002-944063990-9.

31. Bland JM, Altman DG. Statistics notes. The odds ratio. Bmj. 2000; 320:1468.

32. Barrett JC, Fry B, Maller J, Daly MJ. Haploview: analysis and visualization of LD and haplotype maps. Bioinformatics. 2005; 21:263-5. doi: 10.1093/bioinformatics/bth457.

33. Shi YY, He L. SHEsis, a powerful software platform for analyses of linkage disequilibrium, haplotype construction, and genetic association at polymorphism loci. Cell Res. 2005; 15:97-8. doi: 10.1038/sj.cr.7290272. 